\title{
Assessment and Management of Oral Health in Obesity
}

\author{
J. Suvan • F. D'Aiuto
}

Published online: 4 April 2013

(C) Springer Science+Business Media New York 2013

\begin{abstract}
Scientific evidence suggests an association between obesity and oral diseases including periodontal disease, dental caries, tooth erosion, xerostomia, and dentinal hypersensitivity. Optimal oral health is vital in obese patients as a functionally compromised dentition or oral discomfort has been shown to influence dietary habits. However, this essential level of oral health can be a considerable challenge due to the consequences of obesity or obesity therapies. Seemingly minor lifestyle choices and anatomical limitations in obese patients can profoundly affect oral health. Furthermore, the severity of preexisting dental problems has been shown to increase following bariatric surgery. Side effects of medications, bariatric surgery or post-operative dietary recommendations may play a role in this increase. Preventive recommendations supplemented by frequent monitoring of oral status have the potential to maximize oral function and comfort. Collaborative approaches between obesity and dental health professionals should be further investigated to increase awareness and facilitate best care.
\end{abstract}

Keywords Body mass index $\cdot$ Obesity $\cdot$ Periodontitis $\cdot$ Oral health $\cdot$ Xerostomia $\cdot$ Dysphagia $\cdot$ Assessment $\cdot$ Management

\section{Introduction}

Worldwide, at least 2.8 million people die each year as a result of being overweight or obese. For obesity alone,

J. Suvan $(\square) \cdot$ F. D'Aiuto

Unit of Periodontology, Eastman Dental Institute, University

College London (UCL), 256 Gray's Inn Road London,

WC1X 8LD London, UK

e-mail: j.suvan@ucl.ac.uk

F. D'Aiuto

e-mail: f.daiuto@ucl.ac.uk
WHO figures reveal a worldwide prevalence that has doubled between 1980 and 2008 [1]. It is one of a number of non-communicable diseases referred to by the WHO Director-General as slow motion disasters [2] influenced largely by four behavioral lifestyle factors; tobacco use, unhealthy diet, insufficient physical activity and the harmful use of alcohol, many aspects of which are embedded in twentyfirst century social determinants [3]. In addition to obesity's direct adverse effects on general health, numerous comorbidities are the focus of scientific investigations, many of which have common risk factors with complex entangled implications for health [4]. The management of obesity and medical care for obese patients is therefore no simple matter, requiring the understanding, attention and efforts of all healthcare professionals and organizations [5]. It is a condition affecting multiple disciplines and will increasingly demand interdisciplinary approaches to maximize the benefits of all efforts. Oral diseases are one such group of obesity comorbidities sharing some common risk factors with obesity denoting implications for healthcare professionals involved in obesity management as well as dental professionals managing oral health in obese patients $[6 \bullet, 7]$.

\section{Implications of Oral Health in Obesity Management}

Obesity management may entail various strategies many of which include dietary recommendations as a vital component ranging from increase in fresh fruit and vegetables, dietary fibre, alteration in frequency of consumption of liquids or solids, to chewing recommendations. To this extent, the oral cavity and dental status play an important role as oral health status may influence dietary choices or alter compliance of patients with suggested dietary regimes. The WHO defines oral health as "being free of chronic 
mouth and facial pain, oral and throat cancer, oral sores, birth defects such as cleft lip and palate, periodontal disease, tooth decay and tooth loss, and other diseases and disorders that affect the mouth and oral cavity" [8]. The impact of compromised oral health on general health and quality of life is well documented, with detrimental effects resulting from alterations in chewing, swallowing, speech, taste, breathing, choice of nutritional options, appearance, self esteem as well as indirect systemic effects [9-12].

\section{Oral Diseases Associated with Obesity}

A brief overview of the nature of dental diseases together with a summary of current research highlighting associations with obesity provides a framework for understanding assessment and management of oral health in obese patients. For this purpose, oral diseases can crudely be grouped into three categories; periodontal diseases affecting the supporting structures of the teeth, dental diseases affecting the teeth, and oral tissue pathologies affecting any tissues of the mouth, each of which may result in significant discomfort or the ultimate adverse consequence of tooth loss. About $30 \%$ of people worldwide, aged 65-74 have no natural teeth, and only $41 \%$ of Europeans are estimated to have a full dentition [13, 14]. Increasing BMI has been reported in epidemiological studies to be inversely associated with number of teeth present $[15$, 16]. The impact of tooth loss on dietary intake and nutritional status is largely due to changes in masticatory function resulting in reduced intake of healthy foods such as fresh fruits and vegetables, meat, or nuts $[12,17,18]$. Such changes in food choices occur gradually over time, therefore often not recognized by the individual, they are not perceived as influenced by dental comfort or chewing ability. In a recently published study of 999 Swedish women, number of teeth present was statistically associated with obesity. As a continuous variable, an increasing number of teeth were associated with lower BMI, WHR, and WC [19]. These results were in agreement with a similar study in Sweden which indicated an association between edentulism and obesity most obvious in women aged 55-74 years [20].

\section{Periodontitis}

Periodontitis is a chronic inflammatory disease initiated by dental plaque biofilm with its pathogenesis defined by complex inflammatory and immune mechanisms affected by multiple factors $[21,22]$. Present in $20-50 \%$ of the general population and a potential major cause of tooth loss in adults [23-25]. It is characterized by destruction of the periodontal ligament, alveolar bone and junctional epithelium, all part of the supporting structures of the teeth [26]. The clinical manifestations include gingival inflammation resulting in edema, erythema, gingival bleeding or suppuration, periodontal pocket formation, gingival recession, alveolar bone loss, tooth mobility, and eventually tooth loss [27, 28]. Disease manifestation together with levels of discomfort associated with these signs and symptoms varies dramatically among individuals [29]. Based upon the hypothesis that systemic inflammation associated with obesity may affect susceptibility to chronic infectious diseases, the association between obesity and periodontitis has been investigated over the last 15 years. Meta-analyses as part of a recent systematic review of 33 included studies indicated statistically significant associations between periodontitis and body mass index (BMI) category obese OR 1.81 $(1.42,2.30)$, overweight OR $1.27(1.06,1.51)$ and obese and overweight combined OR $2.13(1.40,3.26)$ (Fig. 1) [6•]. Clinical evidence suggests that obese individuals have an increased local inflammatory response [30] as well as possibly an altered oral microflora [31]. As host response to local bacterial challenge is a key factor in determining periodontitis susceptibility [32], an increased inflammatory state as occurs in obese individuals could predispose them to increased periodontal tissue destruction, therefore further compromising oral health status [33].

\section{Caries}

Dental caries is characterized by a loss of localized tooth structure. Its etiology, being acidic by-products of bacterial plaque fermentation of dietary carbohydrates, can be exacerbated by altered salivary factors [34]. It is the most common chronic disease found in children [8]. Globally, it affects 60$90 \%$ of individuals and has been reported to be increasing over the past 20 years. It is a major cause of tooth loss and more prevalent in low socio-economic areas [8]. A recently published systematic review of obesity and dental caries revealed a significant relationship between childhood obesity and dental caries with the relationship stronger for permanent dentitions than primary dentitions. The authors suggest this may be due to an increase in unhealthy diet, in particular frequency and choice of snack foods that coincides with increasing age into adolescence. When separated into industrialized and newly industrialized regions, results were significant for the former but not the latter [35॰]. As noted earlier, the increase in dental caries associated with sugary drinks and snacks is not entirely new and has been increasing, however one could argue that diligence in obese children is even more important considering the multiple factors that potentially may compromise oral health during the lifetime of these children.

\section{Oral Pathologies}

Most common oral pathologies include oral cancers and oral mucositis. Oral cancers are a significant component of the 


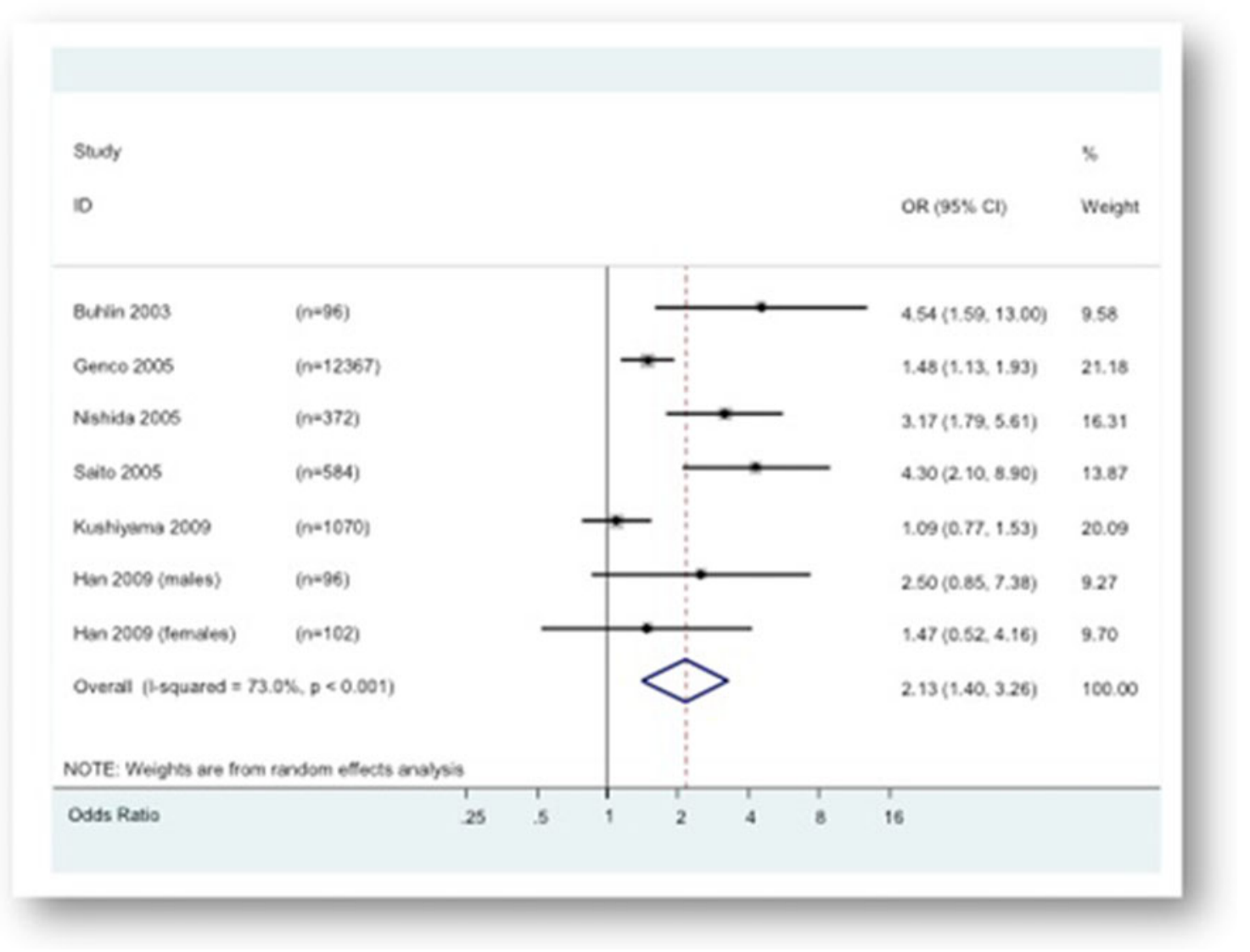

Fig. 1 Forest plot overweight and obese individuals compared with normal (BMI). (From: Suvan J, D'Aiuto F, Moles DR, Petrie A, Donos N. Association between overweight/obesity and periodontitis in adults. A systematic review. Obes Rev. 2011;12(5):e381-e404) [6•]

global burden of cancer [36]. Dental plaque biofilm, smoking, alcohol, medications, dietary factors and genetics have all been implicated in cancer etiology [37]. Contributing dietary factors are linked to low fruit and vegetable diets (or high fat and carbohydrate diets) [37]. One recent publication suggests an elevated risk for oral cancer associated with obesity, however further investigation is needed to confirm these findings [9]. Forms of mucositis are more difficult to quantify in terms of prevalence as they are often cited in the context of other conditions or symptoms. The most common mucositis is xerostomia (sensation of dry mouth). It is reported to affect up to $27 \%$ of middle aged and elderly people and have a dramatic impact on lifestyle [38]. It is characterized by an alteration of the quantity or quality of saliva produced and can result in significant pain and burning sensation of the oral tissues. The role of saliva is often underestimated and includes elements such as lubrication (speaking, chewing, swallowing), buffering action, clearance of food particles and bacteria, maintenance of tooth integrity through self cleansing action, antibacterial action, taste and digestion regulation $[39,40]$. The accepted range of normal flow for unstimulated saliva is anything $>0.1 \mathrm{~mL} / \mathrm{min}$. Any unstimulated flow rate below $0.1 \mathrm{~mL} / \mathrm{min}$ is considered hypo-function. Common causes of dry mouth are dehydration, mouth breathing, anxiety, depression, poorly controlled diabetes, or medication use, in particular anticholinergic drugs, appetite depressants, and diuretics to name a few [39, 40]. Swedish researchers reported selfperceived dry mouth to be associated with obesity in a recent cross-sectional study [19]. An earlier comparison investigated salivary habituation to a taste stimulus of BMI normal vs. BMI obese found salivary habituation delayed compared to controls [41]. Obese patients may have increased susceptibility to dry mouth, particularly if they suffer from obstructive sleep apnea or take medications that alter saliva flow. At the same time, saliva is vital to facilitate consumption of healthy diets and maintenance of oral health. Further research is indicated to confirm prevalence and effects of hypo-salivation among obese patients.

\section{The Double Challenge}

In the context of the outlined dental diseases, it is clear that maintaining optimal oral health plays a key role in obesity management primarily due to its impact on dietary habits. 
However, oral health status in obese patients is more often compromised and particularly challenging to manage. The attention of both obesity management teams and dental professionals is warranted with assessment as the first critical step forward followed by collaborative management strategies.

\section{Oral Health Assessment}

Access to Care A practical suggestion to health professionals is to ask when they last had a dental assessment. Use of dental services has been reported to be lower among obese than non-obese patients [19]. A number of factors could explain this finding. Obese individuals may have more important health issues that consume their attention, hence dental visits fall low on the priority list. Most dental offices do not have facilities to accommodate a full range of obese patients. Standard dental chairs are commonly rated to accommodate $135 \mathrm{~kg}$ static load without considering possibility to lift or recline [42]. Higher levels of dental anxiety have been reported to be associated with obesity [16]. Further investigation in this area may provide clues as to lack of willingness to visit the dentist.

Current Untreated Dental Conditions Does the patient have any existing oral pain, discomfort, or awareness of untreated conditions? A few screening questions can give clues to undiagnosed caries or periodontitis;

1/ Do your gums bleed when you clean your teeth?

2/ Are your teeth sensitive when eating or drinking something hot, cold or sweet?

3/ Are any of your teeth loose?

The potential for a worsening of existing dental conditions in obese patients together with the importance of compliance with dietary recommendations would suggest referral for completion of dental treatment prior to complex obesity management therapies that may affect the oral environment [43].

Removable Dental Prosthesis Does the patient have removable dental prosthesis and if so, do they wear them to eat or only when going out for social occasions as is often the case? If they do not wear them, it could be due to the status of the oral tissues or possibly reduced saliva flow. Prosthetic replacement can be complex due to differing anatomical features in their mouth including increased cheek and tongue size, therefore particular modifications may be necessary to facilitate denture retention [44].

Masticatory Function Does the patient have all their teeth or how many have been lost and where? Is the patient aware of difficulties while chewing on one side of their mouth or the other? Or overall? Do they bite their cheeks or tongue often? Do they avoid or dislike particular foods because chewing seems to take a long time? Preliminary studies in dentistry have reported an association between reduced chewing force and higher BMI regardless of number of teeth [45]. A study investigating masticatory performance in children found that BMI normal children performed better on masticatory performance tests than BMI overweight/obese or BMI underweight [46].

Salivary Flow/Function Subjective assessment of saliva flow is based upon a single positive response to any of the following five questions [47];

1/ Does your mouth feel dry?

2/ Does your mouth feel dry whilst eating?

3/ Do you have difficulty swallowing dry foods?

4/ Do you sip liquids to aid swallowing?

5/ Is the amount of saliva in our mouth too little most of the time?

Some patients may report a burning sensation or altered taste associated with the dryness.

Medications Keep an up to date record of medications taken by the patient including any changes. For quick identification, it may be beneficial to have a list of all medications with dry mouth as a side effect for quick reference. If a patient is taking a medication suspect of altering saliva, be sure to ask the listed questions to obtain their subjective assessment of saliva.

Mouth Breathing/Obstructive Sleep Apnea Simple observation of the patient during consultation can provide clues of possible mouth breathing. Mouth breathing may occur for various reasons of which OSA is one. Mouth breathing leads to drying of the anterior oral tissues sometimes resulting in gingivitis and/or mucositis partially due to the drying effect on bacterial plaque accumulations which tend to be increased. It is often associated with uncontrolled tongue thrust that often obstructs toothbrush placement during oral hygiene self-care. A diligent oral hygiene routine is imperative. Oral appliance therapy for OSA is often a lifelong treatment that carries the risk of dental side effects. Therefore, these patients should have thorough follow-up by a dental specialist experienced in dental sleep medicine [48]. It is suggested that healthcare workers confirm with patients that they are attending regular dental visits.

Oral Hygiene For the dental profession, the approach is aimed at controlling/removing the dental plaque biofilm as being implicated in almost all dental diseases. For obesity management clinicians, any reinforcement of the benefits of 
frequent and thorough oral hygiene to maintaining a functioning dentition will strengthen the patient's awareness of the importance of oral health. Encouraging regular dental check-up visits allows dental professionals the opportunity to support obese patients in managing their oral hygiene effectively. Empathy with them and being careful not to undermine their efforts to clean their mouth is vital. A number of anatomical factors could negatively influence oral hygiene routines in obese individuals. Large cheeks sometimes obstruct access to posterior teeth. In addition, the forearm and upper arm size may restrict bending and positioning of the arm to a suitable position for brush placement. If placed correctly, movement of the brush can be difficult. Based on the vast evidence of the efficacy of power toothbrushes in plaque removal [49], it is likely that for most obese patients a power brush would be recommended, however specific evidence in this area is lacking and oral hygiene devices should always be agreed on an individual basis with the patient.

\section{Oral Health Management}

The previously outlined elements of assessment are already a form of oral health management of obese patients, potentially serving to evoke referral to the dental office for specific assessment and care. Further facets of management may arise in response to individual needs or collateral effects of specific obesity therapies. In particular, various oral health issues associated with bariatric surgical care have been identified and continue to be the focus of investigations directed toward ascertaining best care of these patients.

Masticatory Function Chewing time, cycles and frequency were compared (using five standard foods) in 44 obese patients scheduled for gastric bypass surgery and 30 nonobese control patients. Results showed higher values in the fully dentate for the morbid obese compared to controls. Furthermore, those who were obese and not fully dentate could not produce a food bolus with the same particle size distribution as the fully dentate obese patients. The authors suggested this emphasizes the need for dental evaluation including chewing ability for all patients scheduled for bariatric surgery [50]. Before and after comparisons of bolus formation has been assessed before and after surgery demonstrating changes in bolus granulometry was dependent on food and dental status [51•]. It may be necessary to recommend increased chewing time to patients according to dental status [43].

Post-Operative Adverse Effects and Lifestyle Changes Bariatric surgery post-operative adverse effects and required lifestyle changes may put patients at risk of additional or worsening oral health conditions [52-54]. In particular, gastric reflux and post-surgical meal patterns are responsible for increased risks of dental erosion, caries, mucosal irritations and dentinal hypersensitivity [52]. Heling reported dentinal hypersensitivity prevalence of $37 \%$ in 113 patients who had undergone bariatric surgery [53]. Gastroesophageal reflux disease and/or vomiting expose the oral environment to high levels of acidity ( $\mathrm{pH} 1.2$ ) [55]. The critical $\mathrm{pH}$ for dissolution of tooth structure is 5.5 [56••]. Therefore, the potential for erosion, caries, and tooth sensitivity can be significant, particularly if any of the dental conditions are pre-existing. Hence the recommendation that a dental check-up take place prior to bariatric surgery to ensure no presence of untreated conditions [54].

Post bariatric surgery dietary recommendations include eating small meals more frequently (4-6 times per day), thorough and slow chewing and sipping of fluids throughout the day. Unfortunately, these recommendations are equitable to a substantially increased risk of tooth destruction as they lengthen the time of exposure of potentially damaging low $\mathrm{pH}$ levels $[56 \bullet \cdot$. Saliva normally serves as a buffer following ingestion of acidic substances, and has antibacterial effects, however as previously described, salivary flow is often compromised in obese patients [19,57]. Attention should be given to choosing fluids with less acidic $\mathrm{pH}$ when sipping fluids between meals. Table 1 is an example list of $\mathrm{pH}$ levels of common liquids many of which are surprisingly acidic [56••]. Minimizing ingestion of sugars is key to maintaining $\mathrm{pH}$ levels above 5.5. If candies or gum are used to stimulate saliva flow, these should be limited to sugar free options.

Effects on Periodontitis An improvement in periodontal status post bariatric surgery has been proposed based upon the hypothesis of improved metabolic control and reduction in systemic pro-inflammatory mediators. However, results to date are somewhat unclear. One investigation reported statistically significant difference in response to periodontal therapy rendered following weight loss of $40 \%$ at 6 months post-surgical compared to the response in those individuals

Table $1 \mathrm{pH}$ of common beverages

\begin{tabular}{ll}
\hline Drink & $\mathrm{pH}$ \\
\hline Battery acid & 1.0 \\
Stomach acid & 2.0 \\
Cranberry juice & 2.3 \\
Vegetable juice & $3.9-4.3$ \\
Mountain dew & 3.22 \\
Diet mountain dew & 3.34 \\
Diet gatorade & 2.4 \\
Milk & 6.8 \\
Water & 7.0 \\
\hline
\end{tabular}


who had no surgery and no change in weight. However, the magnitude of the change in periodontal clinical measurements was extremely small putting the clinical significance in question [58]. Comparison of cross sectional data from periodontal assessment of 133 individuals pre-operative compared to $72 \leq 6$ months post-operative compared with $140 \geq 6$ months post-operative revealed lowest prevalence of periodontitis in the group who had surgery $\geq 6$ months prior, however noted an increase in the first months post-surgical [59]. Assessment of 54 bariatric surgery patients before, 3 months, and 6 months after surgery reported worsening periodontal status at 3 and 6 months post-surgical [54].

Due to the multiple risks of changes to the oral cavity following bariatric surgery, routine dental examination and oral hygiene support before, during and after bariatric surgery is proposed. However, the access to care remains a challenge, as many dental facilities are not equipped to manage obese patients. For this reason, it is suggested that bariatric surgical care teams may also play a role in recommendation of basic preventive strategies to minimize the risk of oral health deterioration following bariatric surgery.

\section{Preventive Strategies}

Substantial benefits are feasible through some simple oral health prevention strategies applicable to all individuals regardless of BMI but highly relevant to obese patients.

\section{Oral Hygiene}

- Perform regular brushing twice per day and interdental cleaning a minimum of once per day

- Avoid brushing immediately following ingestion of acidic drinks or foods in order to minimize risk of erosion

- Use products that contain fluoride and spit out rather than rinse out to maximize benefit

\section{Eating and Drinking}

- Avoid acidic drinks when possible

- Use a straw if drinking acidic fluids

- Drink milk or eat cheese to reduce mouth acidity

- Avoid grazing (high frequency snacking)

- Avoid sugary and sticky snacks between meals

- Eat raw vegetables and high fibre foods

- Chew sugar free gum or use sugar free candies if using these between meals to alleviate the feeling of dry mouth or halitosis.

Tobacco use should be avoided and alcohol consumption minimized.
These recommendations are somewhat generic and may need to be individualized as appropriate, however they highlight key underlying principles of oral health promotion.

\section{Conclusions}

Maintaining a high level of oral health is of paramount importance management of obese individuals. Simple assessment and management steps provide opportunities for improved care. Further scientific investigations of oral health associations and interconnecting issues in obese individuals are indicated to explore the nature and determine the magnitude of effects. Increased awareness by both dental and obesity management clinicians/researchers together with collaborative interdisciplinary disease management approaches have the potential to maximize the benefits of care provided in each discipline.

Conflict of Interest J Suvan declares that she has no conflict of interest.

F D'Aiuto declares that he has no conflict of interest.

\section{References}

Papers of particular interest, published recently, have been highlighted as:

- Of importance,

•- Of major importance

1. WHO. Global Health Observatory: Obesity. Available at http:// www.who.int/gho/ncd/risk_factors/obesity_text/en/. Accessed January 2013. 2013. Report.

2. Chan, Dr Margaret Director-General of the World Health Organization. Obesity: bad trouble is on it way. Available at http:// www.who.int/dg/speeches/2012/forum 20120921/en/index.html. Accessed January 2013. 9-21-2012. Report.

3. WHO. Global Status Report on Noncommunicable Diseases 2010. Available at www.who.int/nmh/publications/ncd_report2010/. Accessed January 2013. 2011. Report.

4. Kopelman P. Health risks associated with overweight and obesity. Obes Rev. 2007;8 Suppl 1:13-7.

5. Freedhoff Y, Sharma AM, Kirk SFL, Vallis M, Poirier P, Ball GDC, et al. Realistic first steps for effectively managing obesity in Canada. Clinical Obesity. 2012;2:78-82.

6. - Suvan J, D'Aiuto F, Moles DR, Petrie A, Donos N. Association between overweight/obesity and periodontitis in adults. A systematic review. Obes Rev. 2011;12(5):e381-404. This publication comprises a thorough summary of evidence and metaanalyses with results supporting the association between periodontitis and obesity. Included is discussion of possible mechanisms and implications.

7. Mathus-Vliegen EM, Nikkel D, Brand HS. Oral aspects of obesity. Int Dent J. 2007;57(4):249-56.

8. Petersen PE, Bourgeois D, Ogawa H, Estupinan-Day S, Ndiaye C. The global burden of oral diseases and risks to oral health. Bull World Health Organ. 2005;83(9):661-9. 
9. Choi S, Lee J, Park J, Yun Y, Kim M. Association of body mass index with oral cancer risk. J Korean Assoc Maxillofac Plast Reconstr Surg. 2011;33(6):512-9.

10. Naka O, Anastassiadou V, Pissiotis A. Association between functional tooth units and chewing ability in older adults: a systematic review. Gerodontology. 2012.

11. Sheiham A, Steele JG, Marcenes W, Finch S, Walls AW. The impact of oral health on stated ability to eat certain foods; findings from the National diet and nutrition survey of older people in Great Britain. Gerodontology. 1999;16(1):11-20.

12. Tsakos G, Herrick K, Sheiham A, Watt RG. Edentulism and fruit and vegetable intake in low-income adults. J Dent Res. 2010;89(5):462-7.

13. WHO. Oral Health Fact Sheet No 318 April 2012. Available at www.who.int/mediacentre/factsheets/fs318/en/index.html. Accessed January 2013. 201. Report.

14. Eurobarometer 72.3 Co-ordinated by Directorate General Communication. Oral Health. Available at http://ec.europa.eu/public opinion/ archives/ebs/ebs_330_en.pdf. Accessed January 2013. 2010. Report.

15. Sheiham A, Steele JG, Marcenes W, Finch S, Walls AW. The relationship between oral health status and body mass index among older people: a national survey of older people in Great Britain. Br Dent J. 2002;192(12):703-6.

16. Forslund HB, Lindroos AK, Blomkvist K, Hakeberg M, Berggren $\mathrm{U}$, Jontell M, et al. Number of teeth, body mass index, and dental anxiety in middle-aged Swedish women. Acta Odontol Scand. 2002;60(6):346-52.

17. Nowjack-Raymer RE, Sheiham A. Numbers of natural teeth, diet, and nutritional status in US adults. J Dent Res. 2007;86(12):1171-5.

18. Ervin RB, Dye BA. The effect of functional dentition on Healthy Eating Index scores and nutrient intakes in a nationally representative sample of older adults. J Public Health Dent. 2009;69(4):207-16.

19. Ostberg AL, Bengtsson C, Lissner L, Hakeberg M. Oral health and obesity indicators. BMC Oral Health. 2012;12:50.

20. Osterberg T, Dey DK, Sundh V, Carlsson GE, Jansson JO, Mellstrom D. Edentulism associated with obesity: a study of four national surveys of 16416 Swedes aged 55-84 years. Acta Odontol Scand. 2010;68(6):360-7.

21. Kornman KS, Page RC, Tonetti MS. The host response to the microbial challenge in periodontitis: assembling the players. Periodontol 2000. 1997;14:33-53.

22. Petersen PE, Ogawa H. The global burden of periodontal disease: towards integration with chronic disease prevention and control. Periodontol 2000. 2012;60(1):15-39.

23. Albandar JM, Rams TE. Global epidemiology of periodontal diseases: an overview. Periodontol 2000. 2002;29:7-10.

24. Papapanou PN. Periodontal diseases: epidemiology. Ann Periodontol. 1996;1(1):1-36.

25. Petersen PE, Baehni PC. Periodontal health and global public health. Periodontol 2000. 2012;60(1):7-14.

26. Lindhe J, Karring T, Lang NP. Clinical periodontology and implant dentistry98. Copenhagen: Munksgaard; 1997.

27. Lang NP, Tonetti MS. Periodontal diagnosis in treated periodontitis. Why, when and how to use clinical parameters. J Clin Periodontol. 1996;23:240-50.

28. Page RC. Periodontal diseases: a new paradigm205. J Dent Educ. 1998;62(10):812-21.

29. Page RC, Kornman KS. The pathogenesis of human periodontitis: an introduction. Periodontol 2000. 1997;14:9-11.

30. Lundin M, Yucel-Lindberg T, Dahllof G, Marcus C, Modeer T. Correlation between TNFalpha in gingival crevicular fluid and body mass index in obese subjects. Acta Odontol Scand. 2004;62(5):273-7.

31. Nishimura F, Iwamoto Y, Mineshiba J, Shimizu A, Soga Y, Murayama Y. Periodontal disease and diabetes mellitus: the role of tumor necrosis factor-alpha in a 2-way relationship. J Periodontol. 2003;74(1):97-102.

32. Van Dyke TE, Sheilesh D. Risk factors for periodontitis. J Int Acad Periodontol. 2005;7(1):3-7.

33. Boesing F, Patino JS, da Silva VR, Moreira EA. The interface between obesity and periodontitis with emphasis on oxidative stress and inflammatory response. Obes Rev. 2009;10(3):290-7.

34. Selwitz RH, Ismail AI, Pitts NB. Dental caries. Lancet. 2007;369(9555):51-9.

35. - Hayden C, Bowler JO, Chambers S, Freeman R, Humphris G, Richards D, et al. Obesity and dental caries in children: a systematic review and meta-analysis. Community Dent Oral Epidemiol. 2012. This review provides an overview of current evidence exploring and accounting for the relationship between obesity and dental caries in children.

36. Petersen PE. Oral cancer prevention and control-the approach of the World Health Organization. Oral Oncol. 2009;45(4-5):454-60.

37. Petti S. Lifestyle risk factors for oral cancer. Oral Oncol. 2009;45(4-5):340-50.

38. Nederfors T, Isaksson R, Mornstad H, Dahlof C. Prevalence of perceived symptoms of dry mouth in an adult Swedish populationrelation to age, sex and pharmacotherapy. Community Dent Oral Epidemiol. 1997;25(3):211-6.

39. Nederfors T. Xerostomia and hyposalivation. Adv Dent Res. 2000;14:48-56

40. Visvanathan V, Nix P. Managing the patient presenting with xerostomia: a review. Int J Clin Pract. 2010;64(3):404-7.

41. Bond DS, Raynor HA, Vithiananthan S, Sax HC, Pohl D, Roye GD, et al. Differences in salivary habituation to a taste stimulus in bariatric surgery candidates and normal-weight controls. Obes Surg. 2009;19(7):873-8.

42. Levine R. Obesity and oral disease - a challenge for dentistry. $\mathrm{Br}$ Dent J. 2012;213(9):453-6.

43. de Moura-Grec PG, Marsicano JA, Rodrigues LM, de Carvalho Sales-Peres SH. Alveolar bone loss and periodontal status in a bariatric patient: a brief review and case report. Eur J Gastroenterol Hepatol. 2012;24(1):84-9.

44. Yuan JC, Afshari FS, Lee DJ, Sukotjo C. The impact of obesity on prosthodontic treatment. Gen Dent. 2012;60(6):526-33.

45. Ikebe K, Matsuda K, Morii K, Nokubi T, Ettinger RL. The relationship between oral function and body mass index among independently living older Japanese people. Int J Prosthodont. 2006;19(6):539-46.

46. de Morais Tureli MC, de Souza BT, Gaviao MB. Associations of masticatory performance with body and dental variables in children. Pediatr Dent. 2010;32(4):283-8.

47. Fox PC, Busch KA, Baum BJ. Subjective reports of xerostomia and objective measures of salivary gland performance. J Am Dent Assoc. 1987;115(4):581-4.

48. Doff MH, Finnema KJ, Hoekema A, Wijkstra PJ, de Bont LG, Stegenga B. Long-term oral appliance therapy in obstructive sleep apnea syndrome: a controlled study on dental side effects. Clin Oral Investig. 2013;17(2):475-82.

49. Van der Weijden FA, Campbell SL, Dorfer CE, Gonzalez-Cabezas C, Slot DE. Safety of oscillating-rotating powered brushes compared to manual toothbrushes: a systematic review. J Periodontol. 2011;82(1):5-24.

50. Veyrune JL, Miller CC, Czernichow S, Ciangura CA, Nicolas E, Hennequin M. Impact of morbid obesity on chewing ability. Obes Surg. 2008;18(11):1467-72.

51. - Godlewski AE, Veyrune JL, Nicolas E, Ciangura CA, Chaussain $\mathrm{CC}$, Czernichow S, et al. Effect of dental status on changes in mastication in patients with obesity following bariatric surgery. PLoS One. 2011;6(7):e22324. This study provides a comprehensive description of masticatory function, its assessment and the manner in which dental status may impact chewing and diet in obesity. 
52. Barbosa CS, Barberio GS, Marques VR, Baldo VO, Buzalaf MA, Magalhaes AC. Dental manifestations in bariatric patients: review of literature. J Appl Oral Sci. 2009;17(Suppl):1-4.

53. Heling I, Sgan-Cohen HD, Itzhaki M, Beglaibter N, Avrutis O, Gimmon Z. Dental complications following gastric restrictive bariatric surgery. Obes Surg. 2006;16(9):1131-4.

54. Marsicano JA, Grec PG, Belarmino LB, Ceneviva R, Peres SH. Interfaces between bariatric surgery and oral health: a longitudinal survey. Acta Cir Bras. 2011;26 Suppl 2:79-83.

55. Marsicano JA, de Moura-Grec PG, Bonato RC, Sales-Peres Mde C, Sales-Peres A, Sales-Peres SH. Gastroesophageal reflux, dental erosion, and halitosis in epidemiological surveys: a systematic review. Eur J Gastroenterol Hepatol. 2013;25(2):135-41.

56. •- Lussi A, Megert B, Shellis RP, Wang X. Analysis of the erosive effect of different dietary substances and medications. Br J Nutr.
2012;107(2):252-62. This study reports details of the assessment of $\mathrm{pH}$ and potential damaging effects of an extensive list of common foods and beverages.

57. Marsicano JA, Sales-Peres A, Ceneviva R, de C Sales-Peres $\mathrm{SH}$. Evaluation of oral health status and salivary flow rate in obese patients after bariatric surgery. Eur J Dent. 2012;6(2):191-7.

58. Lakkis D, Bissada NF, Saber A, Khaitan L, Palomo L, Narendran $\mathrm{S}$, et al. Response to periodontal therapy in patients who had weight loss after bariatric surgery and obese counterparts: a pilot study. J Periodontol. 2012;83(6):684-9.

59. Pataro AL, Costa FO, Cortelli SC, Cortelli JR, Dupim Souza AC, Nogueira Guimaraes Abreu MH, et al. Influence of obesity and bariatric surgery on the periodontal condition. J Periodontol. 2012;83(3):257-66. 